\title{
Control Pathways from the Subcortical Limbic Structures to the Trigeminal Motor System in the Lower Brainstem: A Hodological Review
}

\author{
Yukihiko Yasui* \\ Department of Anatomy and Morphological Neuroscience, Shimane University School of Medicine, Izumo, \\ Japan \\ Email: yyasui@med.shimane-u.ac.jp
}

Received 23 February 2015; accepted 8 March 2015; published 11 March 2015

Copyright (C) 2015 by author and Scientific Research Publishing Inc. This work is licensed under the Creative Commons Attribution International License (CC BY). http://creativecommons.org/licenses/by/4.0/

(c) (i) Open Access

\begin{abstract}
The organization of the emotion-related somatic motor behavior, including jaw movements, is governed not only by the cortical limbic system but also by the subcortical limbic system including the amygdala and hypothalamus. GABAergic neurons in the central amygdaloid nucleus (CeA) and glutamatergic neurons in the posterior lateral hypothalamus (PLH) exert inhibitory and excitatory influences, respectively, upon premotor neurons for the motor trigeminal nucleus (Vm) in the parvicellular reticular formation (RFp) of the medulla oblongata. The CeA also has an inhibitory influence on non-dopaminergic (probably GABAergic) neurons in the retrorubral field of the midbrain that send their axons to the RFp. Furthermore, the CeA and lateral hypothalamus including the PLH may also modulate Vm neurons via projections to the mesencephalic trigeminal nucleus which contains the cell bodies of primary afferent neurons conveying inputs from the masticatory muscle spindles or the periodontal ligament receptors to jaw closing motoneurons within the $\mathrm{Vm}$. These pathways from the subcortical limbic structures to the trigeminal motor system in the lower brainstem underlie the regulation of emotional jaw movements.
\end{abstract}

Keywords

Amygdala, Hypothalamus, Motor Trigeminal Nucleus, Jaw Movement, Emotion

\section{Introduction}

Jaw movements are carried out mainly by muscles attached to the mandibular bone, such as the masticatory and

*Corresponding author.

How to cite this paper: Yasui, Y. (2015) Control Pathways from the Subcortical Limbic Structures to the Trigeminal Motor System in the Lower Brainstem: A Hodological Review. Neuroscience \& Medicine, 6, 24-34. 
suprahyoid muscles. The masticatory muscles as well as the mylohyoid muscle and anterior belly of the digastric muscle are innervated by motoneurons in the motor trigeminal nucleus $(\mathrm{Vm})$. Within the $\mathrm{Vm}$, the neurons innervating each muscle are assembled and constitute subgroups. The motoneurons innervating the jaw-closing muscles, such as the masseteric and tempolaris muscles, are assembled in the dorsolateral part of the Vm $(\mathrm{Vm}-\mathrm{dl})$, whereas those innervating the jaw-opening muscles, such as the mylohyoid muscle and anterior belly of the digastric muscle, are assembled in the ventromedial part of the $\mathrm{Vm}(\mathrm{Vm}-\mathrm{vm})$.

The organization of the emotion-related somatic motor behavior, including jaw movements, is governed by neural circuits in the limbic system, which include the amygdala, hypothalamus, and several regions of the cerebral cortex. The amygdala has been known to play a crucial role in the development and expression of emotional behavior, such as the fear reaction and defense response (for review, see [1]-[3]), and has been considered to participate in the control mechanism of jaw movements [4]-[7]. On the other hand, the hypothalamus has been known to be involved in a variety of functions, including not only the control of endocrine and autonomic functions but also motivated and emotional behaviors (for review, see [8]). It is also known that electrical stimulation of the hypothalamus induces attacks or defense responses in which opening and closing movement of jaws is one of the obvious elements [9]-[11].

In this communication, I summarize recent neuroanatomical and neurochemical studies on the control pathways to the Vm from the subcortical limbic structures, such as the amygdala and hypothalamus.

\section{Premotor Neuron Pools for Vm}

Jaw movements are carried out by Vm motoneurons activated by inputs from the periphery and/or from the upper motor centers. Most of these inputs are transmitted to the $\mathrm{Vm}$ via interneurons called premotor neurons. The Vm-premotor neurons send their axons directly to the Vm and many of them are distributed in the lower brainstem, such as the pons and medulla oblongata [12]-[14]. In particular, most of them are found in the sensory trigeminal nuclei including the mesencephalic, principal and spinal trigeminal nuclei, as well as in the lateral reticular formation including the reticular formation around the $\mathrm{Vm}$, parvicellular reticular nucleus (RFp), and intermediate reticular nucleus (IRt) of the pontomedullary and medullary brainstem (Figure 1); the reticular formation around the $\mathrm{Vm}$ adjoins the RFp, and includes the supratrigeminal region dorsal to the $\mathrm{Vm}$, intertrigeminal region between the principal sensory trigeminal nucleus and the $\mathrm{Vm}$, juxtatrigeminal region medial to the Vm and reticular formation ventral to the Vm. The Vm-premotor neurons, except for neurons of the mesencephalic trigeminal nucleus (Vmes), are generally distributed bilaterally, and play an important role in the initiation and regulation of jaw movements by acting as interneurons in the brainstem reflexes, as well as by transmitting information from the upper motor centers to the Vm motoneurons. On the other hand, Vmes neurons that innervate jaw-closing muscle spindles and periodontal mechanoreceptors [15]-[17] send their axons ipsilaterally

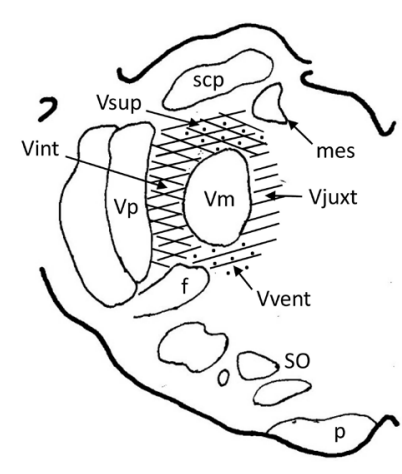

(a)

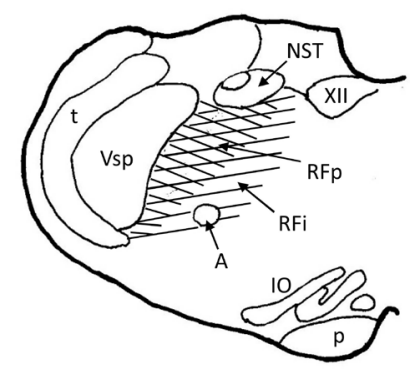

(b)

Figure 1. Illustrations showing the premotor neuron pools for the motor trigeminal nucleus (Vm) in the pons (a) and medulla oblongata (b). In (a), cross-hatched area, hatched area, cross-hatched area with small dots and hatched area with small dots indicate intertrigeminal region (Vint), juxtatrigeminal region (Vjuxt), supratrigeminal region (Vsup) and reticular formation ventral to the $\mathrm{Vm}$ (Vvent), respectively. In (b), cross-hatched area and hatched area indicate parvicellular reticular formation (RFp) and intermediate reticular nucleus (RFi), respectively. A, ambiguus nucleus; f, facial nerve; IO, inferior olivary complex; mes, mesencephalic trigeminal tract; NST, nucleus of the solitary tract; $p$, pyramis; SO, superior olivary complex; $t$, spinal trigeminal tract; Vsp, spinal trigeminal nucleus; Vp, principal trigeminal nucleus; XII, hypoglossal nucleus. 
to Vm motoneurons for controlling jaw movements [16] [18].

\section{Descending Pathways from the Amygdala to the Vm}

\subsection{Neuroanatomical Organization}

As for the possible pathways relaying output signals of the amygdala to the $\mathrm{Vm}$, the direct pathway from the central amygdaloid nucleus (CeA) to the $\mathrm{Vm}$ has been suggested by Mascaro et al. [19], who observed retrogradelabeled neurons in the CeA after injecting Fluoro-gold (FG) into the Vm. However, studies using injection of biotinylated dextran amine (BDA) into the CeA have shown BDA-labeled fibers with bouton-like varicosities around the Vm but not within the Vm, suggesting the unlikely existence of a direct CeA-Vm pathway [20] [21]. On the other hand, the disynaptic pathway from the CeA to the Vm via the supratrigeminal region [22] or via the RFp of the pons [23] has been suggested by anatomical studies using a combined degeneration and horseradish peroxidase method. A physiological study [6] also indicated the existence of disynaptic inputs from the amygdala to the Vm motoneurons mediated by the supratrigeminal region. It is well known, however, that the descending fibers from the CeA are distributed in the RFp not only of the pons but also of the medulla oblongata [24]-[26]. Furthermore, the RFp of the medulla oblongata contains many trigeminal premotor neurons that project directly to the $\mathrm{Vm} \mathrm{[12]-[14]} \mathrm{[27]} \mathrm{[28].} \mathrm{Taken} \mathrm{together,} \mathrm{these} \mathrm{data} \mathrm{make} \mathrm{it} \mathrm{likely} \mathrm{that} \mathrm{the} \mathrm{CeA} \mathrm{also} \mathrm{exerts}$ its influences on the regulation of jaw movements through the pathway from the CeA to the $\mathrm{Vm}$ via the RFp of the medulla oblongata. We therefore demonstrated the existence of a CeA-RFp-Vm pathway by using a combination of anterograde and retrograde tracing techniques [20]. When ipsilateral injections of BDA into the CeA and cholera toxin $\mathrm{B}$ subunit $(\mathrm{CTb})$ into the $\mathrm{Vm}$ were made in the rat, the prominent overlapping distribution of BDA-labeled axons and CTb-labeled neurons was found in the RFp region just ventral to the nucleus of the solitary tract and medial to the spinal trigeminal nucleus throughout the caudalmost part of the pons and the rostral half of the medulla oblongata (Figure 2). Within the neuropil of the RFp region, BDA-labeled axons made symmetrical synaptic contacts predominantly with dendrites and additionally with somata of the RFp neurons, some of which were labeled with $\mathrm{CTb}$.

According to Gonzales and Chesselet [29], a dense projection from the CeA is observed in the lateral part of the substantia nigra (SN) pars compacta as well as in the SN pars lateralis. Not only the lateral part of the SN pars reticulata but also the lateral part of the SN pars compacta and SN pars lateralis have been known to contain neurons projecting to the reticular region around the Vm [30], as well as to the RFp of the medulla oblongata [31]. Taken together, these data suggest the likely occurrence of a disynaptic pathway from the CeA to the RFp via the $\mathrm{SN}$, which is also considered to be responsible for the control of jaw movements. Experiments using electron microscopy will be necessary in order to establish the existence of this disynaptic pathway.

Gonzales and Chesselet [29], and Wallace et al. [32] have shown that CeA fibers are also densely distributed in the lateral part of the retrorubral field (RRF); the RRF has been considered to be involved in the orofacial motor function [33] [34]. Furthermore, the RRF region contains a population of neurons sending their axons to the RFp of the medullary and pontomedullary brainstem [35] [36]. Judging from the above, it seems probable that the output signals from the CeA have direct influence on the retrorubroreticular pathway in the control of jaw movements. After ipsilateral injections of BDA into theCeA and FG into the RFp, we demonstrated that the prominent overlapping distribution of BDA-labeled axon terminals and FG-labeled neurons was found in the lateral part of the RRF ipsilateral to the injection sites (Figure 3), where the BDA-labeled axon terminals made symmetrical synapses with somata and dendrites of the FG-labeled neurons [37].

Furthermore, the CeA sends projection fibers to the Vmes and Vmes neurons are closely apposed by CeA axonal varicosities [21] [38]; the Vmes contains the somata of primary afferent neurons whose peripheral processes are associated with the muscle spindles of jaw-closing muscles and mechanoreceptors within the periodontal ligaments and most of the central processes terminate in the Vm. Recently, Shirasu et al. [39] showed that many CeA fibers with terminal boutons are distributed in the caudal Vmes and that a part of these terminal buttons formed axo-somatic synapses with Vmes neurons, suggesting that the CeA regulates bite strength by modifying neuronal activity in the Vmes.

\subsection{Neurochemical Organization}

With respect to the neurotransmitter of the CeA neurons, recent in situ hybridization studies demonstrated that 

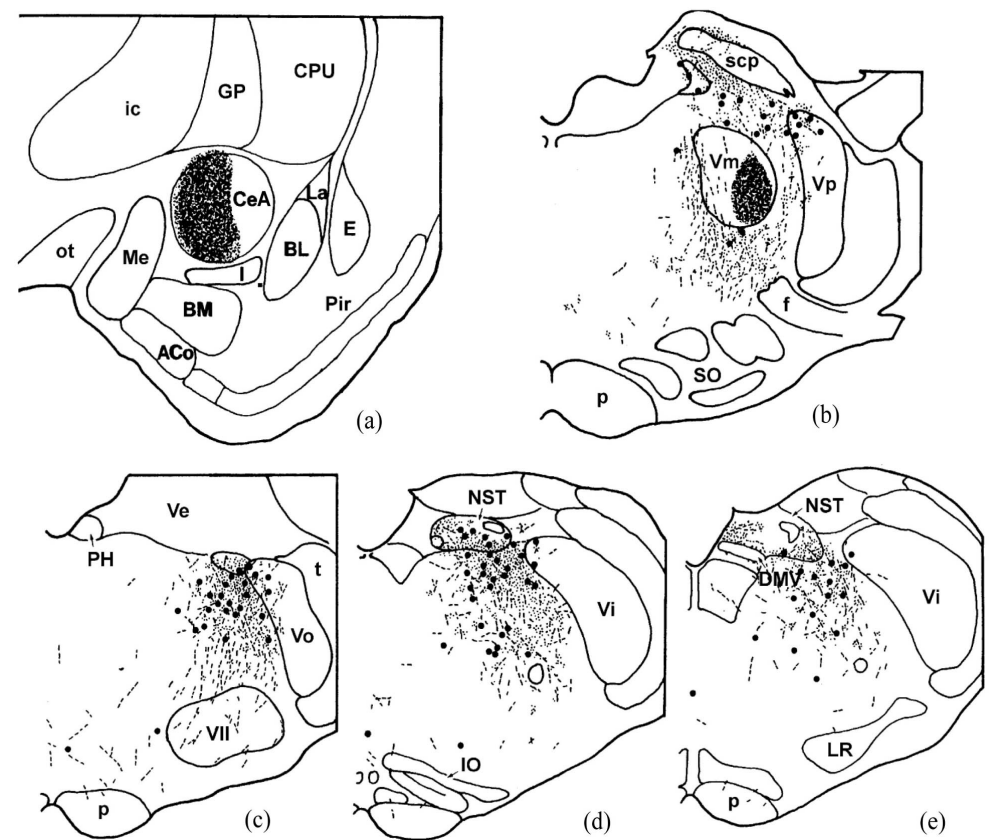

Figure 2. Line drawings showing the sites of biotinylated dextran amine (BDA) injection into the central amygdaloid nucleus $(\mathrm{CeA})$ (shaded area in (a)) and cholera toxin B subunit $(\mathrm{CTb})$ injection into the motor trigeminal nucleus (Vm) (shaded area in (b)), and resulting anterograde and retrograde labeling in the lower brainstem ipsilateral to the injection sites ((b)-(e), rostral to caudal). BDA-labeled fibers and terminals are presented by fine lines and fine dots, respectively. CTb-labeled cell bodies are presented by filled circles, each of which represents about two labeled cell bodies. ACo, anterior cortical amygdaloid nucleus; BL, basolateralamygdaloid nucleus; BM, basomedialamygdaloid nucleus; caudate-putamen; CPU, caudate-putamen; DMV, dorsal motor nucleus of the vagus nerve; E, endopiriform nucleus; GP, globuspallidus; I, interstitial amygdaloid nucleus; ic, internal capsule; La, lateral amygdaloid nucleus; LR, lateral reticular nucleus; ot, optic tract; Me, medial amygdaloid nucleus; PH, prepositus hypoglossal nucleus; Pir, piriform cortex; Ve, vestibular nucleus; Vi, interpolarsubnucleus of the spinal trigeminal nucleus; Vo, oral subnucleus of the spinal trigeminal nucleus; VII, facial nucleus. Other abbreviations are as shown in Figure 1.

almost all the CeA neurons are positive for glutamic acid decarboxylase (GAD) 65 mRNA [40] and GAD67 mRNA [41] but not for vesicular glutamate transporter (VGLUT) 1 mRNA [40] and VGLUT2 mRNA [40] [41]; GAD is an enzyme that converts glutamate to GABA and is a marker for GABAergic neurons, while VGLUT1 and VGLUT2 are a marker for glutamatergic neurons. These data support the idea that CeA neurons are GABAergic. Recently, we demonstrated for the first time that almost all the CeA axon terminals in the RRF are immunoreactive for GAD [37]. Such GABAergicCeA axon terminals have also been observed in other brainstem regions including the parabrachial nucleus [42] and nucleus of the solitary tract [43] [44], as well as in the forebrain regions including the parastrial nucleus [45] and lateral hypothalamic area [46] [47].

The SN contains many dopaminergic neurons, which are distributed mainly in the pars compacta, referred to as the A9 dopamine cell group. The RRF also contains numerous dopaminergic neurons that are referred to as the A8 dopamine cell group. However, SN neurons projecting to the brainstem regions, such as the inferior colliculus [48] and reticular formation around the $\mathrm{Vm}$ [30], have been revealed not to be immunonegative for tyrosine hydroxylase (TH), which catalyzes the rate-limiting step in the synthesis of catecholamine. Recently, we also demonstrated that RRF neurons projecting to the RFp are not immunonegative for TH [37]. Taken together, these data suggest that both the SN and RRF neurons sending their axons to the lower brainstem are non-dopaminergic and probably GABAergic [49]. Studies combining retrograde tract-tracing with immunolabeling for GABA or GAD or with in situ hybridization for GAD mRNA should help to demonstrate this idea.

The RFp is heterogeneous with respect to neurotransmitter phenotypes; glutamatergic, GABAergic, cholinergic, and nitrergic neurons are all found in the RFp [50]. According to Pang et al. [51], VGLUT2-immunoreactive axon terminals, which are distributed in both the Vm-dl and the Vm-vm, originate from Vm-premotor neurons. Travers et al. [50] indicated that approximately half of Vm-premotor neurons in the RFp and IRt are immunoreactive for VGLUT2. On the other hand, it has been reported that inhibitory Vm-premotor neurons immuno 


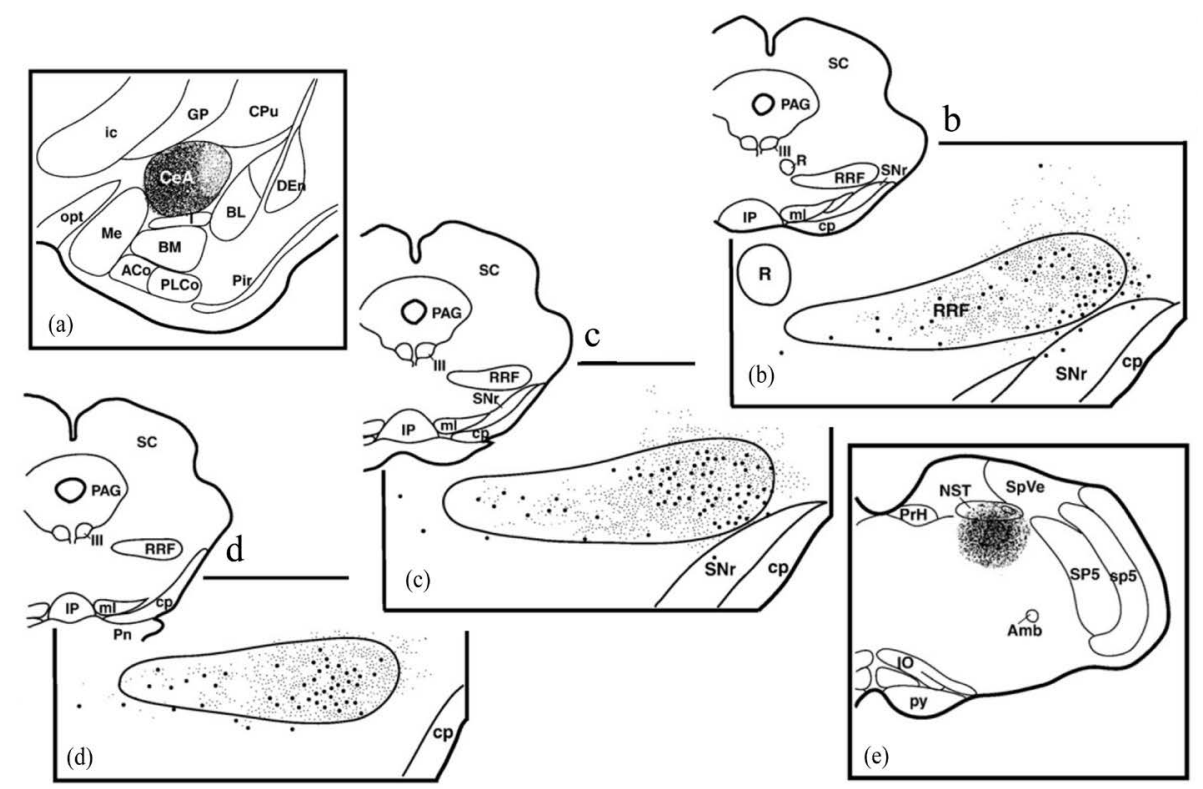

Figure 3. Line drawings illustrating the sites of biotinylated dextran amine (BDA) injection into the central amygdaloid nucleus (CeA) (shaded area in (a)) and Fluoro-gold (FG) injection into the parvicellular reticular formation(shaded area in (e)), and resulting distributions of BDA-labeled terminals (small dots) and FG-labeled neurons (large dots) in the retrorubral field (RRF) region ((b)-(d), rostral to caudal). Each RRF region in the midbrain section (b)-(d) is enlarged in (b)-(d), respectively. Amb, ambiguous nucleus; cp, cerebral peduncle; Den, dorsal endopiriform nucleus; IP, interpeduncular nucleus; ml, medial lemniscus; PAG, periaqueductal gray; PLCo, posterolateral cortical nucleus; Pn, pontine nucleus; PrH, prepositus hypoglossal nucleus; py, pyramis; R, red nucleus; SC, superior colliculus; SNr, substantia nigra pars reticulata; $\mathrm{SpVe}$, spinal vestibular nucleus; SP5, spinal trigeminal nucleus; sp5, spinal trigeminal tract; III, oculomotor nucleus. Other abbreviations are as shown in Figure 1 and Figure 2.

reactive for GAD or glycine are also distributed in the RFp [52]. Recently, Travers et al. [50] indicated that a quarter of Vm-premotor neurons in the RFp and IRt are immunoreactive for GAD65/67. Travers et al. [50] also indicated that relatively few Vm-premotor neurons in the RFp and IRt are either nitrergicor cholinergic.

Vmes neurons have been indicated to be glutaminergic [53] [54]. A recent study revealed that VGLUT1 is expressed in both the central axon terminals and the peripheral sensory endings of Vmes neurons and further that VGLUT1 mRNA is expressed in the cell bodies of Vmes neurons [55]. These data suggest that Vmes neurons are glutamatergic.

\section{Descending Pathways from the Hypothalamus to the Vm}

\subsection{Neuroanatomical Organization}

The hypothalamic projection to the Vm has been examined by using retrograde tracers [19] [56]. McGregor et al. [56] found retrogradely labeled neurons in the dorsomedial hypothalamic nucleus, perifornical nucleus and LHA after $\mathrm{CTb}$ injection into the $\mathrm{Vm}$. Furthermore, Mascaro et al. [19] observed retrogradely labeled neurons in the posterior lateral hypothalamus (PLH) region just medial to the subthalamic nucleus after FG injection into the Vm; this PLH region has been identified as the parasubthalamic nucleus by Wang and Zang [57]. However, we found only some passing BDA-labeled fibers without bouton-like varicosities within the Vm after BDA injection into the PLH, suggesting the unlikely existence of a direct PLH-Vm pathway [58]. There have been no anterograde tracing studies to indicate the direct hypothalamo-Vm projections from the paraventricular, dorsomedial, and perifornical nuclei as well as from the LHA although a couple of peptidergic projections from the LHA to the Vm have been reported as describe below.

Shammah-Lagnado et al. [59] investigated the afferent connection of the rat RFp systematically by using retrograde tracing with horseradish peroxidase, and indicated that RFp-projecting hypothalamic neurons are located predominantly in the LHA, additionally in the parvicellular division of the paraventricular nucleus, and occasionally in the dorsomedial nucleus. Recently, we observed nearly the same distribution pattern of RFp- 
projecting hypothalamic neurons and indicated that the highest number of RFp-projecting neurons is located in the PLH region just medial to the subthalamic nucleus [58]. Using a combined anterograde and retrograde tracing technique, we further showed that the prominent overlapping distribution of PLH fibers and Vm-premotor neurons in the RFp region just ventral to the nucleus of the solitary tract and medial to the spinal trigeminal nucleus (Figure 4), and that the PLH axon terminals make an asymmetrical synaptic contact predominantly with dendrites and additionally with somata of the RFp neurons, some of which were labeled with CTb injected into the Vm.

Interestingly, anterograde tracing studies with Phaseolus vulgaris-leucoagglutinin [60] [61] or with BDA [46] have been indicated that the PLH receives a dense projection from the CeA. In light of these data, it seems likely that RFp-projecting PLH neurons are under the direct influence of the CeA.

\subsection{Neurochemical Organization}

Neumerous hypothalamic neurons labeled with $\mathrm{CTb}$ injected into the $\mathrm{Vm}$ region have been revealed to display glutamate-like immunoreactivity [56]. Recently, VGLUT has been considered to be a much better marker for glutamatergic neurons [62], and it has been reported that LHA neurons express predominantly VGLUT2 mRNA and additionally VGLUT1 mRNA [63]. In addition, the axon terminals with glutamate immunoreactivity [64][66] or with VGLUT2 immunoreactivity [67] have been reported to make asymmetrical synapses with their target structures. In accordance with the above-mentioned data, we demonstrated that the PLH axon terminals with VGLUT2 immunoreactivity make asymmetrical synapses with RFp neurons, suggesting that glutamatergic PLH neurons exert excitatory influence upon RFp neurons.

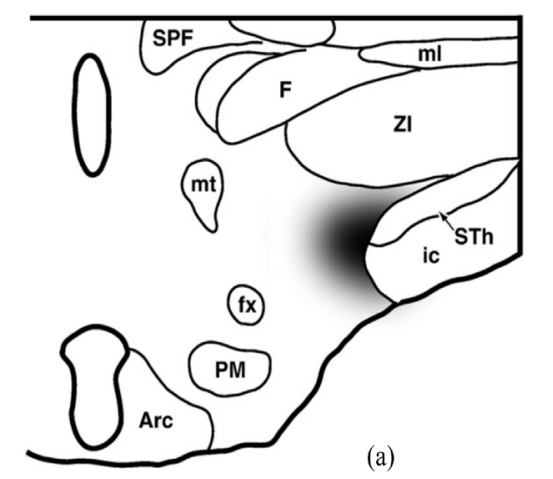

(a)
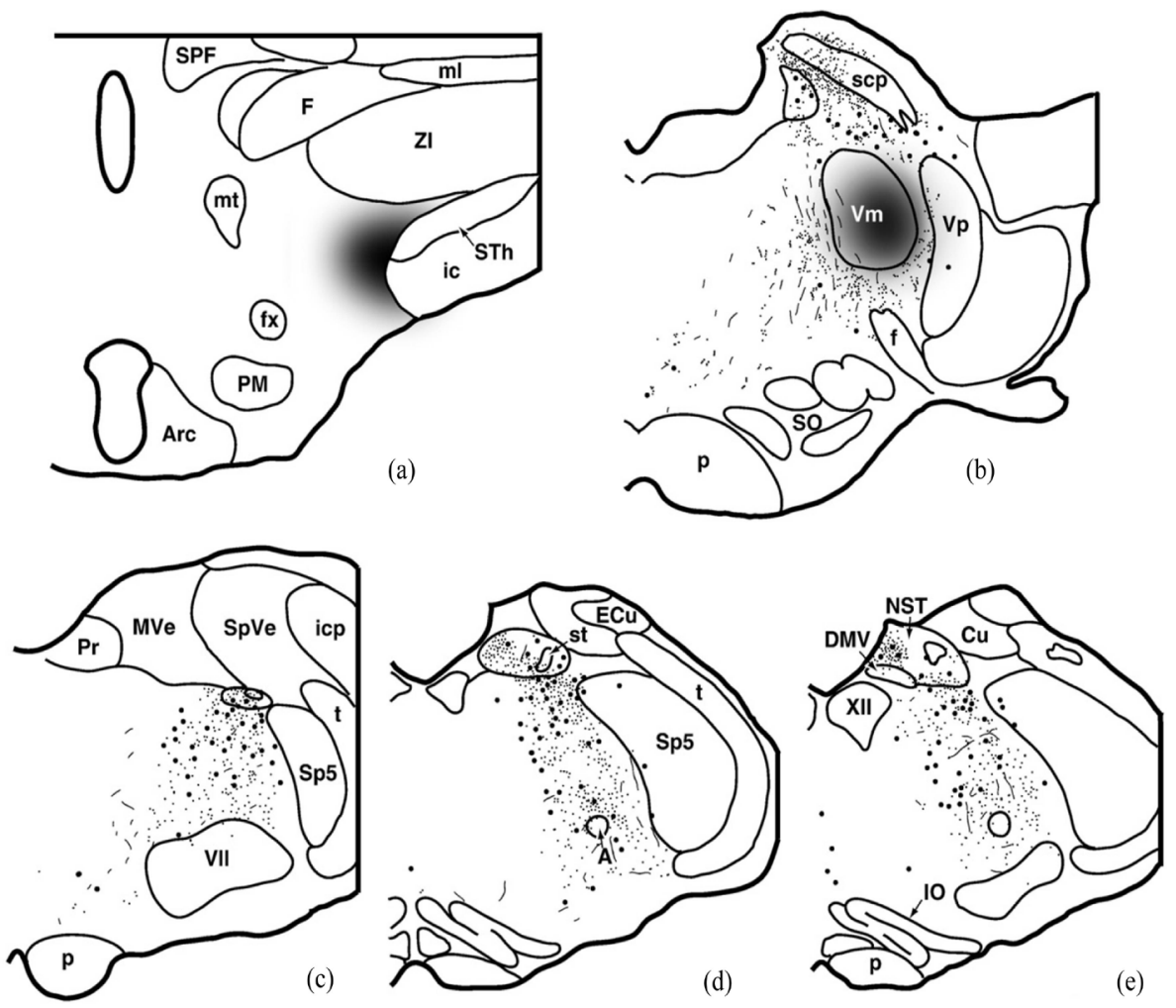

Figure 4. Line drawings showing the sites of biotinylated dextran amine (BDA) injection into the posterior lateral hypothalamus (shaded area in (a)) and cholera toxin B subunit (CTb) injection into the motor trigeminal nucleus (Vm) (shaded area in (b)), and resulting anterograde and retrograde labeling in the lower brainstem ipsilateral to the injection sites ((b)-(e), rostral to caudal). BDA-labeled fibers and terminals are presented by fine lines and fine dots, respectively. CTb-labeled cell bodies are presented by filled circles, each of which represents about two labeled cell bodies. Arc, arcuate nucleus; $\mathrm{Cu}$, cuneate nucleus; $\mathrm{ECu}$, external cuneate nucleus; $\mathrm{F}$, nucleus of the fields of Forel; fx, fornix; icp, inferior cerebellar peduncle; mt, mammillothalamic tract; MVe, medial vestibular nucleus; PM, premammillary nucleus; Pr, prepositus hypoglossal nucleus; SPF, subparafacicular nucleus; st, solitary tract; STh, subthalamic nucleus; ZI, zona incerta. Other abbreviations are as shown in Figures 1-3. 


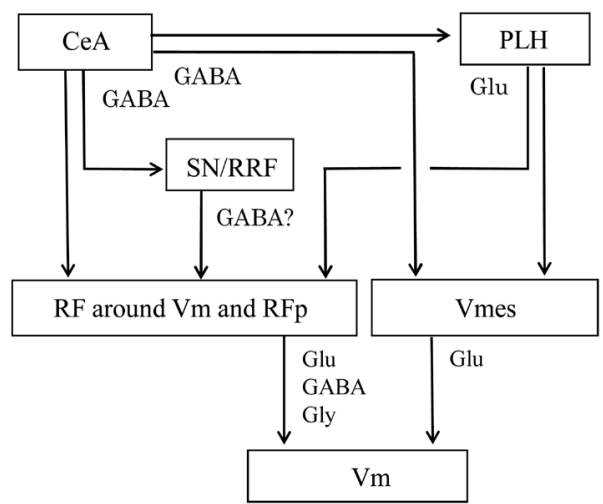

Figure 5. Summary diagram showing the control pathways from the central amygdaloid nucleus (CeA) and posterior lateral hypothalamus (PLH) to the motor trigeminal nucleus $(\mathrm{Vm})$, both subcortical limbic structures control jaw movements through their direct projections to Vm-premotor neurons in the reticular formation (RF) around the Vm in the pons, parvicellular reticular formation (RFp) in the pontomedullary and medullary brainstem, as well as in the mesencephalic trigeminal nucleus (Vmes). In addition, the CeA control jaw movements through its indirect projections to these premotor neuron pools via the substantia nigra (SN)/retrorubral field (RRF). The neurotransmitter(s) used in each pathway are also indicated. Glu, glutamate; Gly, glycine.

As for the neuropeptides, by using retrograde tracing in combination with immunohistochemical methods, recent studies in the cat [68] and rat [69] have demonstrated at the light microscopic level that hypothalamic orexinergic/hypocretinergic fibers are in contact with $\mathrm{Vm}$ motoneurons, although there are only sparse orexinergic fibers in the Vm. More recently, Mascaro et al. [38] demonstrated that orexinergic fibers are distributed in the $\mathrm{Vm}$ and that approximately one-third of the LHA neurons sending their axons to the Vm are immunoreactive for orexin. McGregor et al. [56], who also found orexinergic Vm-premotor neurons in the LHA, further indicated that $\mathrm{Vm}$-premotor neurons in the LHA as well as in the perifornical nucleus are immunoreactive for melanin concentrating hormone $(\mathrm{MCH})$. Saito et al. [70] have demonstrated that $\mathrm{MCH}$-immunoreactive fibers are distributed in the $\mathrm{Vm}$ where many neurons express $\mathrm{MCH}$ receptor mRNA, suggesting that the $\mathrm{MCH}$ system may be related to the processes underlying mastication. Mascaro et al. [38] and Zhang and Luo [69] have also observed orexin-immunoreactive fibers in the Vmes where they closely contact the Vmes neuronal somata, suggesting that orexinergic fibers are involved not only in the control of mastication but also in the genesis of nocturnal bruxism.

\section{Conclusion}

This article summarizes neuroanatomical and neurochemical organization of the control pathways to the Vm from the subcortical limbic structures, such as the amygdala and hypothalamus. The summary diagram is shown in Figure 5. The CeA and PLH innervate the Vm through their direct or indirect projections to Vm-premotor neurons including RFp and Vmes neurons. These projections belong to the lateral component of the emotional motor system that controls specific emotional motor activities (see [71] [72], for review). The RFp is the major premotor neuron pool not only for the Vm but also for the facial and hypoglossal nuclei. Therefore, the amygdala and hypothalamus are thought to control the orofacial muscles during aggression, freezing or other emotional behaviors through their projections to the orofacial motor nuclei via the RFp.

\section{Acknowledgements}

The author is grateful for the support of Drs. R. Fujimoto, K. Fujita, T. Goeku, M. Kuzushima, T. Mukai, Y. Munenaga, T. Sakurai, Y. Sakurai, H. Taguchi, K. Tanaka, K. Urashima, H. Yamaoka, S. Yamazaki and K. Yoshida. This study was partly supported by Grant-in-Aid for Scientific Research (C) (19500294, 21500325 and 24500412) from the Ministry of Education, Science, Sports and Culture of Japan.

\section{References}

[1] Davis, M. (1992) The Role of the Amygdala in Fear and Anxiety. Annual Review of Neuroscience, 15, 353-375. 
http://dx.doi.org/10.1146/annurev.ne.15.030192.002033

[2] Holstege, G. (1991) Descending Motor Pathways and the Spinal Motor System: Limbic and Non-Limbic Components. In: Holstege, G., Ed., Role of the Forebrain in Sensation and Behavior, Elsevier, Amsterdam, 307-421.

[3] LeDoux, J.E. (2000) Emotion Circuits in the Brain. Annual Review of Neuroscience, 23, 155-184. http://dx.doi.org/10.1146/annurev.neuro.23.1.155

[4] Mishima, K., Sasamoto, K. and Ohta, M. (1982) Amygdaloid or Cortical Facilitation of Antidromic Activity of Trigeminal Motoneurons in the Rat. Comparative Biochemistry and Physiology Part A: Physiology, 73, 355-359. http://dx.doi.org/10.1016/0300-9629(82)90167-0

[5] Nakamura, Y. and Kubo, Y. (1978) Masticatory Rhythm in Intracellular Potential of Trigeminal Motoneurons Induced by Stimulation of Orbital Cortex and Amygdala in Cats. Brain Research, 148, 504-509. http://dx.doi.org/10.1016/0006-8993(78)90738-2

[6] Ohta, M. and Moriyama, Y. (1986) Supratrigeminal Neurons Mediate Shortest, Disynaptic Pathway from the Central Amygdaloid Nucleus to the Contralateral Trigeminal Motoneurons in the Rat. Comparative Biochemistry and Physiology Part A: Physiology, 83, 633-641. http://dx.doi.org/10.1016/0300-9629(86)90702-4

[7] Sasamoto, K. and Ohta, M. (1982) Amygdaloid-Induced Jaw Opening and Facilitation or Inhibition of the Trigeminal Motoneurons in the Rat. Comparative Biochemistry and Physiology Part A: Physiology, 73, 349-354. http://dx.doi.org/10.1016/0300-9629(82)90166-9

[8] Card, J., Swanson, L.W. and Moore, Y. (2003) The Hypothalamus: An Overview of Regulatory Systems. In: Bloom, F.E., Landis, S.C., Roberts, J.L., Squire, L.R. and Zigmond, M.J., Eds., Fundamental Neuroscience, 2nd Edition, Academic Press, San Diego, 897-909.

[9] Brody, J.F., DeFeudis, P.A. and DeFeudis, F.V. (1969) Effects of Micro-Injections of L-Glutamate into the Hypothalamus on Attack and Flight Behaviour in Cats. Nature, 224, 1330. http://dx.doi.org/10.1038/2241330a0

[10] Brown, J.L., Hunsperger, R.W. and Rosvold, H.E. (1969) Defence, Attack, and Flight Elicited by Electrical Stimulation of the Hypothalamus of the Cat. Experimental Brain Research, 8, 113-129.

[11] Chi, C.C. and Flynn, J.P. (1971) Neural Pathways Associated with Hypothalamically Elicited Attack Behavior in Cats. Science, 171, 703-706. http://dx.doi.org/10.1126/science.171.3972.703

[12] Travers, J.B. and Norgren, R. (1983.) Afferent Projections to the Oral Motor Nuclei in the Rat. Journal of Comparative Neurology, 220, 280-298. http://dx.doi.org/10.1002/cne.902200303

[13] Li, Y.-Q., Takada, M., Kaneko, T. and Mizuno, N. (1995) Premotor Neurons for Trigeminal Motor Nucleus Neurons Innervating the Jaw-Closing and Jaw-Opening Muscles: Differential Distribution in the Lower Brainstem of the Rat. Journal of Comparative Neurology, 356, 563-579. http://dx.doi.org/10.1002/cne.903560407

[14] Ter Horst, G.J., Copray, J.C.V.M., Liem, R.S.B. and Van Willigen, J.D. (1991) Projections from the Rostral Parvicellular Reticular Formation to Pontine and Medullary Nuclei in the Rat: Involvement in Autonomic Regulation and Orofacial Motor Control. Neuroscience, 40, 735-758. http://dx.doi.org/10.1016/0306-4522(91)90009-D

[15] Jerge, C.R. (1963) Organization and Function of the Trigeminal Mesencephalic Nucleus. Journal of Neurophysiology, 26, 379-392.

[16] Nomura, S. and Mizuno, N. (1985) Differential Distribution of Cell Bodies and Central Axons of Mesencephalic Trigeminal Nucleus Neurons Supplying the Jaw-Closing Muscles and Periodontal Tissue: A Transganglionic Tracer Study in the Cat. Brain Research, 359, 311-319. http://dx.doi.org/10.1016/0006-8993(85)91442-8

[17] Liem, R.S., Copray, J.C. and van Willigen, J.D. (1991) Ultrastructure of the Rat Mesencephalic Trigeminal Nucleus. Acta Anatomica, 140, 112-119. http://dx.doi.org/10.1159/000147045

[18] Luo, P. and Li, J. (1991) Monosynaptic Connections between Neurons of Trigeminal Mesencephalic Nucleus and JawClosing Motoneurons in the Rat: An Intracellular Horseradish Peroxidase Labeling Study. Brain Research, 559, 267275. http://dx.doi.org/10.1016/0006-8993(91)90011-J

[19] Mascaro, M.B., Bittencourt, J.C., Casatti, C.A. and Elias, C.F. (2005) Alternative Pathways for Catecholamine Action in Oral Motor Control. Neuroscience Letters, 386, 34-39. http://dx.doi.org/10.1016/j.neulet.2005.05.062

[20] Yasui, Y., Tsumori, T., Oka, T. and Yokota, S. (2004) Amygdaloid Axon Terminals Are in Contact with Trigeminal Premotor Neurons in the Parvicellular Reticular Formation of the Rat Medulla Oblongata. Brain Research, 1016, 129134. http://dx.doi.org/10.1016/j.brainres.2004.04.080

[21] Lazarov, N.E., Usunoff, K.G., Schmitt, O., Itzev, D.E., Rolfs, A. and Wree, A. (2011) Amygdalotrigeminal Projection in the Rat: An Anterograde Tracing Study. Annals of Anatomy, 193, 118-126. http://dx.doi.org/10.1016/j.aanat.2010.12.004

[22] Takeuchi, Y., Satoda, T. and Matsushima, R. (1988) Amygdaloid Projections to the Commissural Interneurons for Masticatory Motoneurons. Brain Research Bulletin, 21, 123-127. http://dx.doi.org/10.1016/0361-9230(88)90127-X 
[23] Takeuchi, Y., Satoda, T., Tashiro, T., Matsushima, R. and Uemura-Sumi, M. (1988) Amygdaloid Pathway to the Trigeminal Motor Nucleus via the Pontine Reticular Formation in the Rat. Brain Research Bulletin, 21, 829-833. http://dx.doi.org/10.1016/0361-9230(88)90052-4

[24] Hopkins, D.A. and Holstege, G. (1978) Amygdaloid Projections to the Mesencephalon, Pons and Medulla Oblongata in the Cat. Experimental Brain Research, 32, 529-547. http://dx.doi.org/10.1007/BF00239551

[25] Krettek, J.E. and Price, J.L. (1978) Amygdaloid Projections to Subcortical Structures within the Basal Forebrain and Brainstem in the Rat and Cat. Journal of Comparative Neurology, 178, 225-254. http://dx.doi.org/10.1002/cne.901780204

[26] Price, J.L. and Amaral, D.G. (1981) Anautoradiographic Study of the Projections of the Central Nucleus of the Monkey Amygdala. Journal of Neuroscience, 1, 1242-1259.

[27] Mogoseanu, D., Smith, A.D. and Bolam, J.P. (1993) Monosynaptic Innervation of Trigeminal Motor Neurons Involved in Mastication by Neurons of the Parvicellular Reticular Formation. Journal of Comparative Neurology, 336, 53-65. http://dx.doi.org/10.1002/cne.903360105

[28] Yasui, Y., Tsumori, T., Ono, K. and Kishi, T. (1997) Nigral Axon Terminals Are in Contact with Parvicellular Reticular Neurons Which Project to the Motor Trigeminal Nucleus in the Rat. Brain Research, 775, 219-224. http://dx.doi.org/10.1016/S0006-8993(97)00957-8

[29] Gonzales, C. and Chesselet, M.F. (1990) Amygdalonigral Pathway: An Anterograde Study in the Rat with Phaseolus vulgaris Leucoagglutinin (PHA-L). Journal of Comparative Neurology, 297, 182-200. http://dx.doi.org/10.1002/cne.902970203

[30] Yasui, Y., Nakano, K., Nakagawa, Y., Kayahara, T., Shiroyama, T. and Mizuno, N. (1992) Non-Dopaminergic Neurons in the Substantia Nigra Project to the Reticular Formation around the Trigeminal Motor Nucleus in the Rat. Brain Research, 585, 361-366. http://dx.doi.org/10.1016/0006-8993(92)91237-9

[31] Yasui, Y., Tsumori, T., Ando, A. and Domoto, T. (1995) Demonstration of Axon Collateral Projections from the Substantia Nigra Pars Reticulata to the Superior Colliculus and the Parvicellular Reticular Formation in the Rat. Brain Research, 674, 122-126. http://dx.doi.org/10.1016/0006-8993(94)01459-U

[32] Wallace, D.M., Magnuson, D.J. and Gray, T.S. (1992) Organization of Amygdaloid Projections to Brainstem Dopaminergic, Noradrenergic, and Adrenergic Cell Groups in the Rat. Brain Research Bulletin, 28, 447-454. http://dx.doi.org/10.1016/0361-9230(92)90046-Z

[33] Arts, M.P., Bemelmans, F.F. and Cools, A.R. (1998) Role of the Retrorubral Nucleus in Striatally Elicited Orofacial Dyskinesia in Cats: Effects of Muscimol and Bicuculline. Psychopharmacology, 140, 150-156. http://dx.doi.org/10.1007/s002130050752

[34] Uchida, T., Adachi, K., Fujita, S., Lee, J., Gionhaku, N., Cools, A.R. and Koshikawa, N. (2005) Role of GABA(A) Receptors in the Retrorubral Field and Ventral Pallidum in Rat Jaw Movements Elicited by Dopaminergic Stimulation of the Nucleus Accumbens Shell. European Journal of Pharmacology, 510, 39-47. http://dx.doi.org/10.1016/j.ejphar.2005.01.012

[35] von Krosigk, M. and Smith, A.D. (1991) Descending Projections from the Substantia Nigra and Retrorubral Field to the Medullary and Pontomedullary Reticular Formation. European Journal of Neuroscience, 3, 260-273. http://dx.doi.org/10.1111/j.1460-9568.1991.tb00088.x

[36] von Krosigk, M., Smith, Y., Bolam, J.P. and Smith, A.D. (1992) Synaptic Organization of GABAergic Inputs from the Striatum and the Globus Pallidus onto Neurons in the Substantia Nigra and Retrorubral Field Which Project to the Medullary Reticular Formation. Neuroscience, 50, 531-549. http://dx.doi.org/10.1016/0306-4522(92)90445-8

[37] Tsumori, T., Qin, Y., Yokota, S., Niu, J.G. and Yasui, Y. (2009) Central Amygdaloid Axon Terminals Are in Contact with Retrorubral Field Neurons That Project to the Parvicellular Reticular Formation of the Medulla Oblongata in the Rat. Brain Research, 1306, 18-28. http://dx.doi.org/10.1016/j.brainres.2009.09.118

[38] Mascaro, M.B., Prosdócimi, F.C., Bittencourt, J.C. and Elias, C.F. (2009) Forebrain Projections to Brainstem Nuclei Involved in the Control of Mandibular Movements in Rats. European Journal of Oral Science, 117, 676-684. http://dx.doi.org/10.1111/j.1600-0722.2009.00686.x

[39] Shirasu, M., Takahashi, T., Yamamoto, T., Itoh, K., Sato, S. and Nakamura, H. (2011) Direct Projections from the Central Amygdaloid Nucleus to the Mesencephalic Trigeminal Nucleus in Rats. Brain Research, 1400, 19-30. http://dx.doi.org/10.1016/j.brainres.2011.05.026

[40] Poulin, J.F., Castonguay-Lebe, Z., Lafores, S. and Drolet, G. (2008) Enkephalin Co-Expression with Classic Neurotransmitters in the Amygdaloid Complex of the Rat. Journal of Comparative Neurology, 506, 943-959. http://dx.doi.org/10.1002/cne.21587

[41] Oka, T., Tsumori, T., Yokota, S. and Yasui, Y. (2008) Neuroanatomical and Neurochemical Organization of Projections from the Central Amygdaloid Nucleus to the Nucleus Retroambiguus via the Periaqueductal Gray in the Rat. 
Neuroscience Research, 62, 286-298. http://dx.doi.org/10.1016/j.neures.2008.10.004

[42] Jia, H.G., Zhang, G.Y. and Wan, Q. (2005) A GABAergic Projection from the Central Nucleus of the Amygdala to the Parabrachial Nucleus: An Ultrastructural Study of Anterograde Tracing in Combination with Post-Embedding Immunocytochemistry in the Rat. Neuroscience Letters, 382, 153-157. http://dx.doi.org/10.1016/j.neulet.2005.03.013

[43] Jia, H.-G., Rao, Z.-R. and Shi, J.-W. (1997) Evidence of Gamma-Aminobutyricacidergic Control over the Catecholaminergic Projection from the Medulla Oblongata to the Central Nucleus of the Amygdala. Journal of Comparative Neurology, 381, 262-281. http://dx.doi.org/10.1002/(SICI)1096-9861(19970512)381:3<262::AID-CNE2>3.0.CO;2-0

[44] Saha, S., Batten, T.F. and Henderson, Z. (2000) A GABAergic Projection from the Central Nucleus of the Amygdala to the Nucleus of the Solitary Tract: A Combined Anterograde Tracing and Electron Microscopic Immunohistochemical Study. Neuroscience, 99, 613-626. http://dx.doi.org/10.1016/S0306-4522(00)00240-2

[45] Tsubouchi, K., Tsumori, T., Yokota, S., Okunishi, H. and Yasui, Y. (2007) A Disynaptic Pathway from the Central Amygdaloid Nucleus to the Paraventricular Hypothalamic Nucleus via the Parastrial Nucleus in the Rat. Neuroscience Research, 59, 390-398. http://dx.doi.org/10.1016/i.neures.2007.08.010

[46] Tsumori, T., Yokota, S., Qin, Y., Oka, T. and Yasui, Y. (2006) A Light and Electron Microscopic Analysis of the Convergent Insular Cortical and Amygdaloid Projections to the Posterior Lateral Hypothalamus in the Rat, with Special Reference to Cardiovascular Function. Neuroscience Research, 56, 261-269. http://dx.doi.org/10.1016/j.neures.2006.07.005

[47] Nakamura, S., Tsumori, T., Yokota, S., Oka, T. and Yasui, Y. (2009) Amygdaloid Axons Innervate Melanin-Concentrating Hormone- and Orexin-Containing Neurons in the Mouse Lateral Hypothalamus. Brain Research, 1278, 66-74. http://dx.doi.org/10.1016/j.brainres.2009.04.049

[48] Yasui, Y., Nakano, K., Kayahara, T. and Mizuno, N. (1991) Non-Dopaminergic Projections from the Substantia Nigra Pars Lateralis to the Inferior Colliculus in the Rat. Brain Research, 559, 139-144. http://dx.doi.org/10.1016/0006-8993(91)90296-8

[49] Mugnaini, E. and Oertel, W.H. (1985) Atlas of the Distribution of GABAergic Neurons and Terminals in the Rat as Revealed by GAD Immunoreactivity. In: Björklund, A. and Hökfelt, T., Eds., Handbook of Chemical Neuroanatomy: GABA and Neuropeptides in the CNS, Part 1, Vol. 4, Elsevier, Amsterdam, 436-595.

[50] Travers, J.B., Yoo, J.E., Chandran, R., Herman, K. and Travers, S.P. (2005) Neurotransmitter Phenotypes of Intermediate Zone Reticular Formation Projections to the Motor Trigeminal and Hypoglossal Nuclei in the Rat. Journal of Comparative Neurology, 488, 28-47. http://dx.doi.org/10.1002/cne.20604

[51] Pang, Y.W., Ge, S.N., Nakamura, K.C., Li, J.L., Xiong, K.H., Kaneko, T. and Mizuno, N. (2009) Axon Terminals Expressing Vesicular Glutamate Transporter VGLUT1 or VGLUT2 within the Trigeminalmotor Nucleus of the Rat: Origins and Distribution Patterns. Journal of Comparative Neurology, 512, 595-612. http://dx.doi.org/10.1002/cne.21894

[52] Li, Y.Q., Takada, M., Kaneko, T. and Mizuno, N. (1996) GABAergic and Glycinergic Neurons Projecting to the Trigeminalmotor Nucleus: A Double Labeling Study in the Rat. Journal of Comparative Neurology, 373, 498-510. http://dx.doi.org/10.1002/(SICI)1096-9861(19960930)373:4<498::AID-CNE3>3.0.CO;2-X

[53] Kaneko, T., Itoh, K., Shigemoto, R. and Mizuno, N. (1989) Glutaminase-Like Immunoreactivity in the Lower Brainstem and Cerebellum of the Adult Rat. Neuroscience, 32, 79-98. http://dx.doi.org/10.1016/0306-4522(89)90109-7

[54] Chen, P., Li, J.-L., Li, J.-S. and Mizuno, N. (2001) Glutamic Acid Decarboxylase-Like Immunoreactive Axon Terminals in Synaptic Contact with Mesencephalic Trigeminal Nucleus Neurons in the Rat. Neuroscience Letters, 298, 167170. http://dx.doi.org/10.1016/S0304-3940(00)01736-5

[55] Pang, Y.W., Li, J.L., Nakamura, K., Wu, S., Kaneko, T. and Mizuno, N. (2006) Expression of Vesicular Glutamate Transporter 1 Immunoreactivity in Peripheral and Central Endings of Trigeminal Mesencephalic Nucleus Neurons in the Rat. Journal of Comparative Neurology, 498, 129-141. http://dx.doi.org/10.1002/cne.21047

[56] McGregor, R., Damián, A., Fabbiani, G., Torterolo, P., Pose, I., Chase, M. and Morales, F.R. (2005) Direct Hypothalamic Innervation of the Trigeminal Motor Nucleus: A Retrograde Tracer Study. Neuroscience, 136, 1073-1081. http://dx.doi.org/10.1016/j.neuroscience.2005.08.028

[57] Wang, P.Y. and Zang, F.C. (1995) Outline and Atlas of Learning Rat Brain Slices. Northwest University Press, Xi'an.

[58] Notsu, K., Tsumori, T., Yokota, S., Sekine, J. and Yasui, Y. (2008) Posterior Lateral Hypothalamic Axon Terminals Are in Contact with Trigeminal Premotor Neurons in the Parvicellular Reticular Formation of the Rat Medulla Oblongata. Brain Research, 1244, 71-81. http://dx.doi.org/10.1016/j.brainres.2008.09.076

[59] Shammah-Lagnado, S.J., Costa, M.S. and Ricardo, J.A. (1992) Afferent Connections of the Parvocellular Reticular Formation: A Horseradish Peroxidase Study in the Rat. Neuroscience, 50, 403-425. http://dx.doi.org/10.1016/0306-4522(92)90433-3

[60] Bourgeais, L., Gauriau, C. and Bernard, J.F. (2001) Projections from the Nociceptive Area of the Central Nucleus of the Amygdala to the Forebrain: A PHA-L Study in the Rat. European Journal of Neuroscience, 14, 229-255. 
http://dx.doi.org/10.1046/j.0953-816x.2001.01640.x

[61] Tsumori, T., Yokota, S., Kishi, T., Qin, Y., Oka, T. and Yasui, Y. (2006) Insular Cortical and Amygdaloid Fibers Are in Contact with Posterolateral Hypothalamic Neurons Projecting to the Nucleus of the Solitary Tract in the Rat. Brain Research, 1070, 139-144. http://dx.doi.org/10.1016/i.brainres.2005.11.040

[62] Kaneko, T. and Fujiyama, F. (2002) Complementary Distribution of Vesicular Glutamate. Transporters in the Central Nervous System. Neuroscience Research, 42, 243-250. http://dx.doi.org/10.1016/S0168-0102(02)00009-3

[63] Ziegler, D.R., Cullinan, W.E. and Herman, J.P. (2002) Distribution of Vesicular Glutamate Transporter mRNA in Rat Hypothalamus. Journal of Comparative Neurology, 448, 217-229. http://dx.doi.org/10.1002/cne.10257

[64] Clarke, N.P., Bolam, J.P. and Bevan, M.D. (1996) Glutamate-Enriched Inputs from the Mesopontine Tegmentum to the Entopeduncular Nucleus in the Rat. European Journal of Neuroscience, 8, 1363-1376. http://dx.doi.org/10.1111/j.1460-9568.1996.tb01599.x

[65] Gundersen, V., Ottersen, O.P. and Storm-Mathisen, J. (1996) Selective Excitatory Amino Acid Uptake in Glutamatergic Nerve Terminals and in Glia in the Rat Striatum: Quantitative Electron Microscopic Immunocytochemistry of Exogenous (D)-Aspartate and Endogenous Glutamate and GABA. European Journal Neuroscience, 8, 758-765. http://dx.doi.org/10.1111/j.1460-9568.1996.tb01261.x

[66] Tai, Q. and Goshgarian, H.G. (1996) Ultrastructural Quantitative Analysis of Glutamatergic and GABAergic Synaptic Terminals in the Phrenic Nucleus after Spinal Cord Injury. Journal of Comparative Neurology, 372, 343-355. http://dx.doi.org/10.1002/(SICI)1096-9861(19960826)372:3<343::AID-CNE2>3.0.CO;2-2

[67] Fujiyama, F., Hioki, H., Tomioka, R., Taki, K., Tamamaki, N., Nomura, S., Okamoto, K. and Kaneko, T. (2003) Changes of Immunocytochemical Localization of Vesicular Glutamate Transporters in the Rat Visual System after the Retinofugal Denervation. Journal of Comparative Neurology, 465, 234-249. http://dx.doi.org/10.1002/cne.10848

[68] Fung, S.J., Yamuy, J., Sampogna, S., Morales, F.R. and Chase, M.H. (2001) Hypocretin (Orexin) Input to Trigeminal and Hypoglossal Motoneurons in the Cat: A Double-Labeling Immunohistochemical Study. Brain Research, 903, 257262. http://dx.doi.org/10.1016/S0006-8993(01)02318-6

[69] Zhang, J. and Luo, P. (2002) Orexin B Immunoreactive Fibers and Terminals Innervate the Sensory and Motor Neurons of Jaw-Elevator Muscles in the Rat. Synapse, 44, 106-110. http://dx.doi.org/10.1002/syn.10050

[70] Saito, Y., Cheng, M., Leslie, F.M. and Civelli, O. (2001) Expression of the Melanin-Concentrating Hormone (MCH) Receptor mRNA in the Rat Brain. Journal of Comparative Neurology, 435, 26-40. http://dx.doi.org/10.1002/cne.1191

[71] Holstege, G. (1992) The Emotional Motor System. European Journal of Morphology, 30, 67-79.

[72] Holstege, G. (2010) The Emotional Motor System and Micturition Control. Neurology and Urodynamics, 29, 42-48. http://dx.doi.org/10.1002/nau.20789 